\title{
Home Automation through Eyeball Motion for Disabled Persons
}

\section{D.Vijendra Babu, S.K.Sivasubramanian}

\begin{abstract}
Recent Technological advancements have helped the mankind in essential and significant ways. Disabled persons are valued human resource for the nation and a platform to be provided for their effective participation. A prototype is developed for manage the Home appliances with the movement of Eyeball for cursor control. Camera captures the image of movement of eye and it detects the pupil centre position of the eye. The various changes on pupil position gets diverse instruction for the virtual keyboard. Obtained signals permit the motor driver to collaborate with the virtual keyboard. The prototype moves in various directions depending on the selected signal.

Index Terms: camera, disabled, eyeball movement, home automation, pupil.
\end{abstract}

\section{INTRODUCTION}

In India as per 2016 census, the status of Disabled Population is 2.68 Crores persons accounts to $2.21 \%$ of the total population. $69 \%(1.86 \mathrm{Cr})$ of them reside in Rural areas and remaining $31 \%(0.81 \mathrm{Cr})$ resides in Urban areas. Out of it $56 \%$ are Males \& $44 \%$ are Females. The distribution of Disabled persons in age group is summarized as, $17 \%$ in $10-19$ years, $16 \%$ in $20-29$ years \& Elderly (above 60 years) disabled constituted $21 \%$ at all India level. Assistive devices such as mobility devices (wheelchairs, prosthetic devices and walkers), hearing aids, cognitive aids, adaptive switches and utensils, physical modification in build environment plays a major role for disabled persons. Government of India defines as Disability as (a) Blindness,(b) Loco motor disability,(c) Mental illness ,(d) Low vision,(e) Leprosy-cured,(f) Hearing impairment \& (g) Mental retardation Face recognition system helps in various applications and plays a vital role for disabled person's assistance. Eyeball movement tracking helps the disabled persons for operation/controlling of Home appliances.

\section{LITERATURE SURVEY}

P.Viola and M.Jones, 2001 discusses about detection of objects based on the approach of Machine learning and accomplishing prominent detection rates. It was distinguished by three key contributions. It is used in live situations, without shifting to image differencing.A.M.Malla, et all, 2010 discussed about a prototype competent enough to monitor on

Revised Manuscript Received on September 22, 2019.

Dr.D.Vijendra Babu,ECE Department, Aarupadai Veedu Institute of Technology, Vinayaka Mission's Research Foundation, Deemed to be Univesity,Chennai,India. Email:vijendrababu@avit.ac.in

S.K.Sivasubramanian, ECE Department, Aarupadai Veedu Institute of Technology, Vinayaka Mission's Research Foundation, Deemed to be Univesrity,Chennai, India. regular basis of intended person alertness which aids in avoiding accidents due to drowsiness. It discusses about the exactness to differentiate between fully opened, closed and half closed eyes.

S.Vitabile, et all, 2010 discusses about a prototype system to determine the Driver's sleepiness levels to avoid vehicle collisions. It focusses on tracing human eye and determining the sleepiness failures. G.Boustany, et all, 2016 describes about a home automation system been operated by eye movement of disabled persons considering the various parameter such as position of pupil, movement and size to be captured by camera. Adarsh Rajesh, 2017 discuses about a prototype of eyeball based movement controlling the wheelchair utilizing neural networks.

\section{SYSTEM DESIGN}

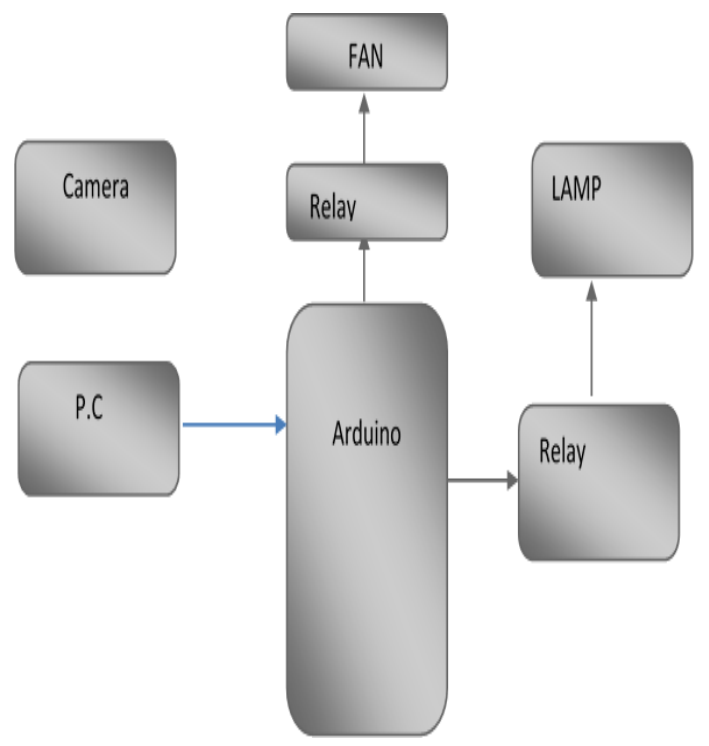

Fig. 1.Block Diagram

Fig. 1 displays the Block diagram of the proposed module.The prototype uses a Webcam and monitoring unit. Depending on the eye movement with the aid of Open CV, the cursor movement is controlled. The system comprises of ARM11 processor in Arduino board is used along with Pyauto GUI library used for cursor movement. 


\section{HARDWARE MODULE}

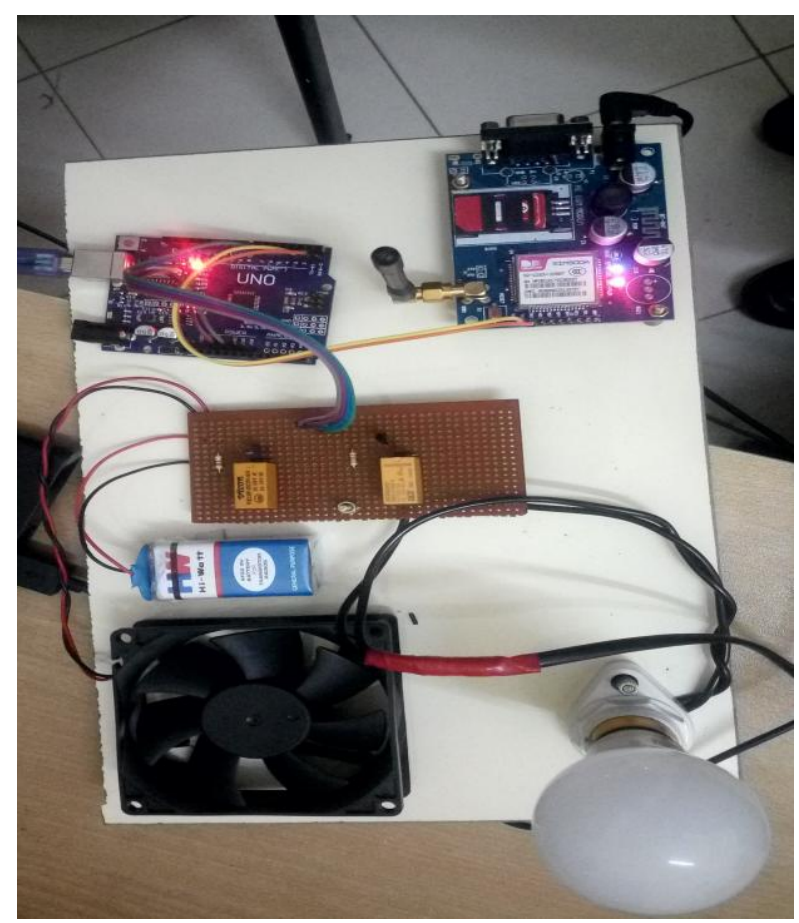

Fig. 2.Snapshot of Hardware module

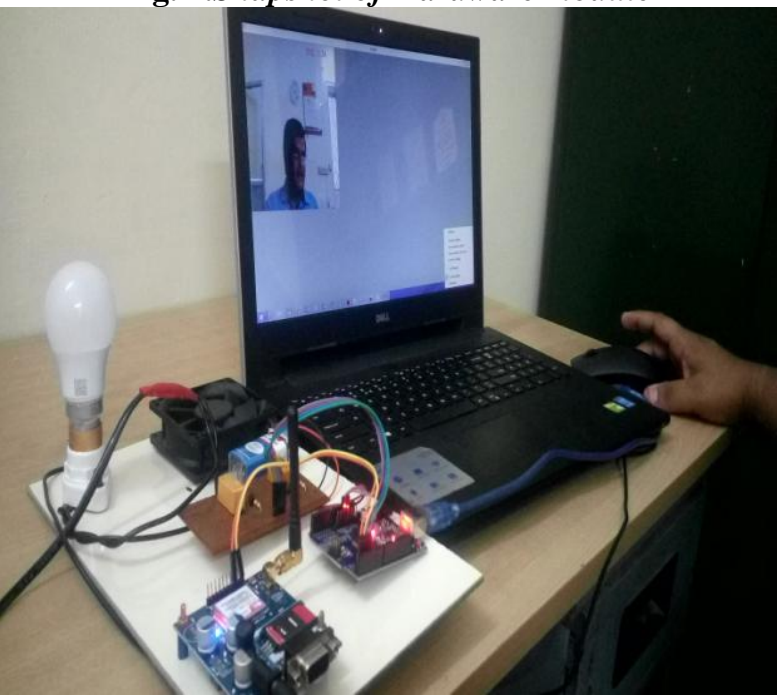

Fig. 3.Snapshot of Proposed Module setup

Fig. 2 displays the snapshot of Hardware module.Fig.3 displays the snapshot of proposed module setup.The Camera captures the Image of Eye movementThe center position value of pupil is made as a reference and then the next the different value of $\mathrm{X}$, Y coordinates will be set for a particular command.The prototype allows the Disabled person to regulate mouse cursor depending on eyeball movement. The position of the Camera should bewith good illuminated condition for effective operation.

\section{RESULT AND DISCUSSION}

Fig.4 displays the demonstration of results. Fig. 5 displays Light is On.Fig.6 displays the snapshot of the right click pressed through eyeball movement.Fig.7 displays the snapshot of the button pressed.Fig.8, Fig.9 \& Fig. 10 displays the snapshot of Fan is On status.Fig.11 displays the snapshot of Fan is On status in prototype.Fig.12, Fig.13 \& Fig.14 displays the snapshot of the prototype experimentation. The
Face Capture \& Recognition system plays an effective tool providing safety and security with active or passive recognition of subjects. The system can stand alone for surveillance purposes or be integrated into access control or other third party systems to enhance functionality.

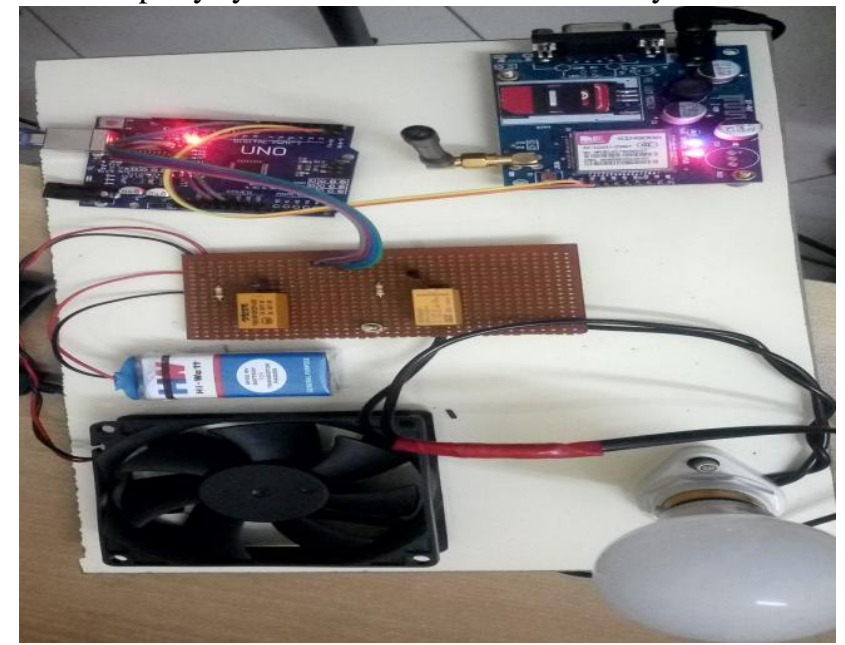

Fig. 4.Demonstartion of Results

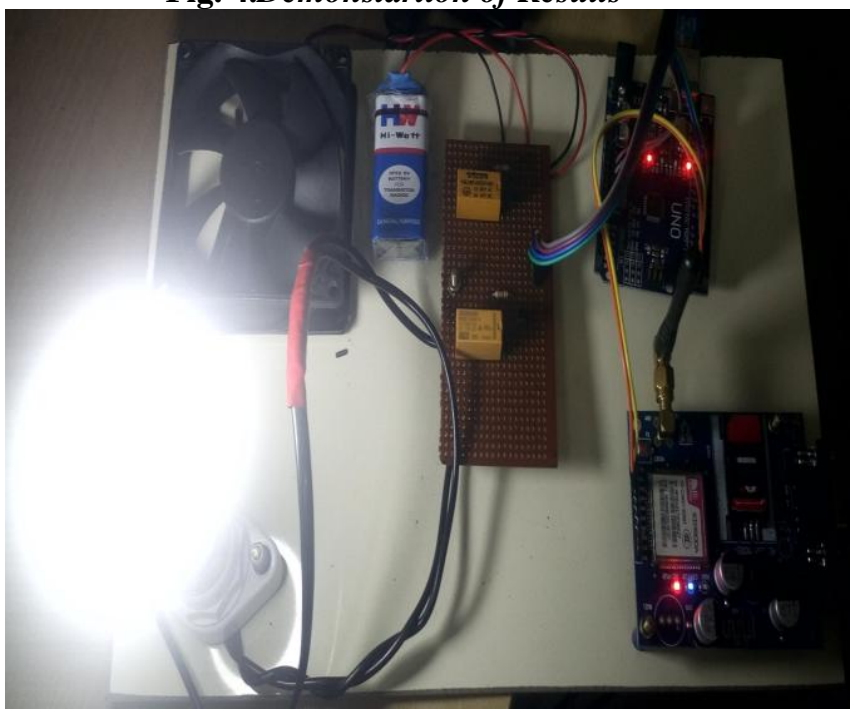

Fig. 5.Snapshot of Light in On status

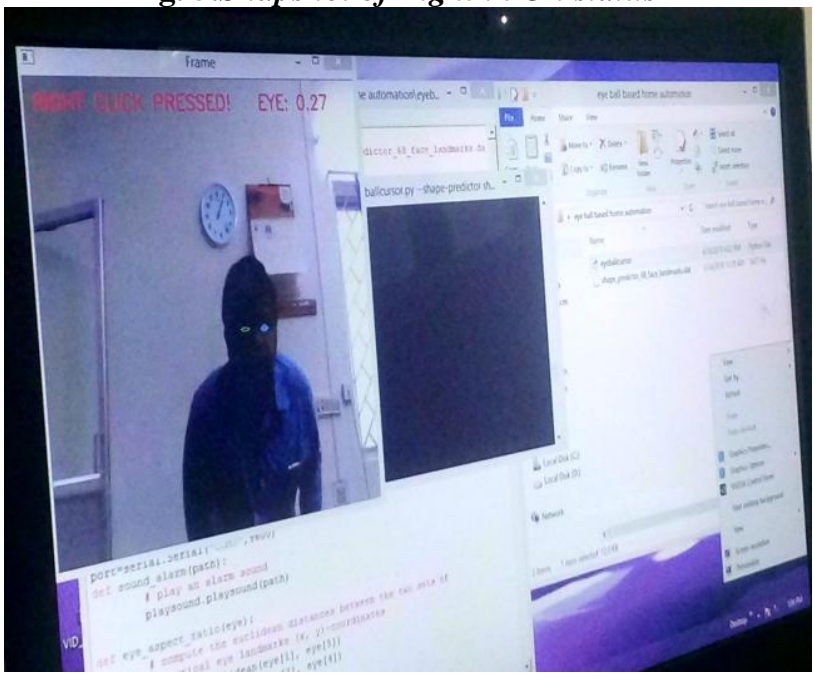

Fig. 6.Snapshot of Right click pressed through eyeball movement

Published By: 


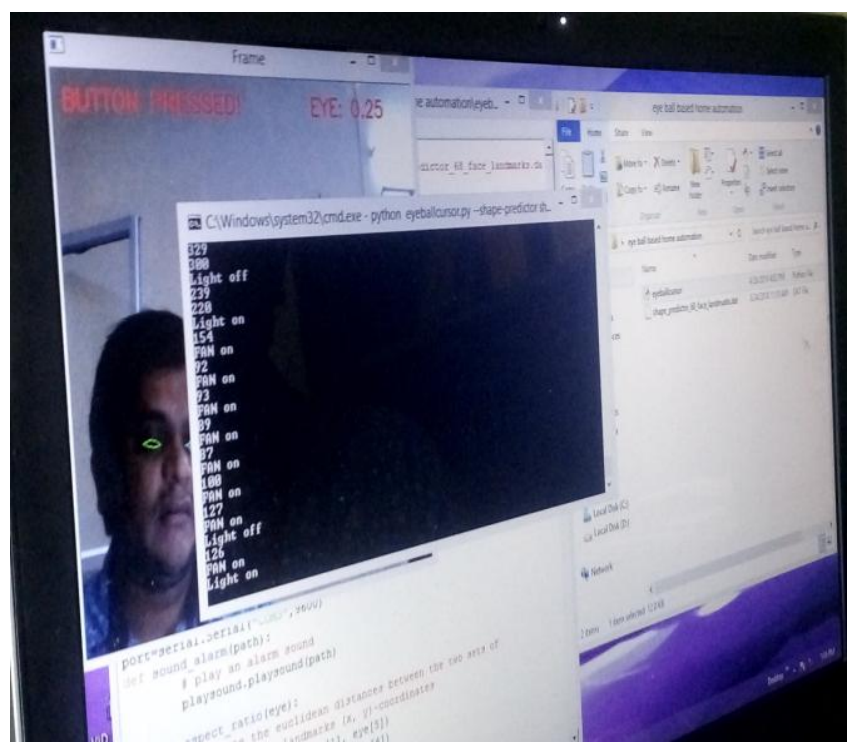

Fig. 7.Snapshot of Button pressed

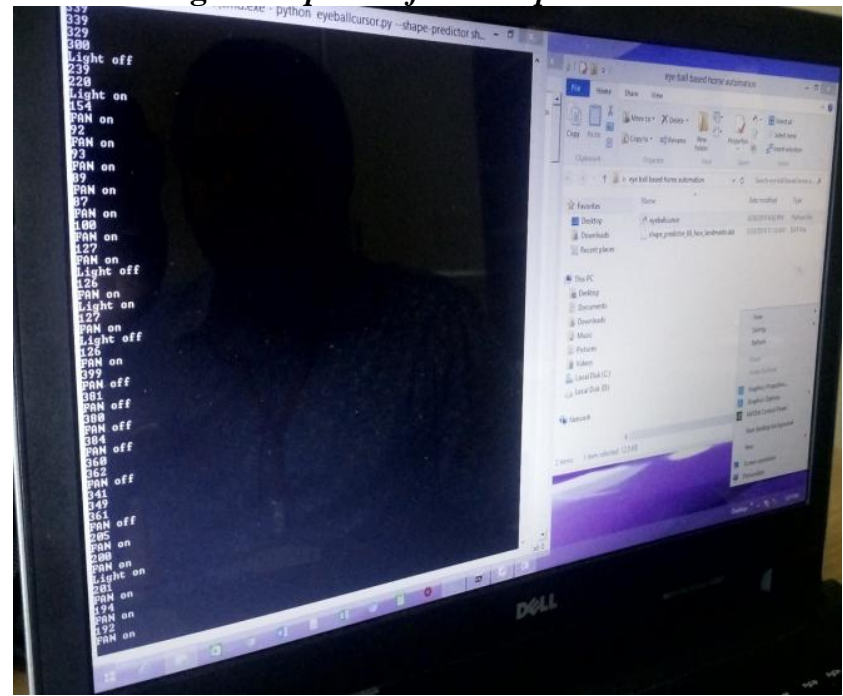

Fig. 8.Snapshot of Fan is On status

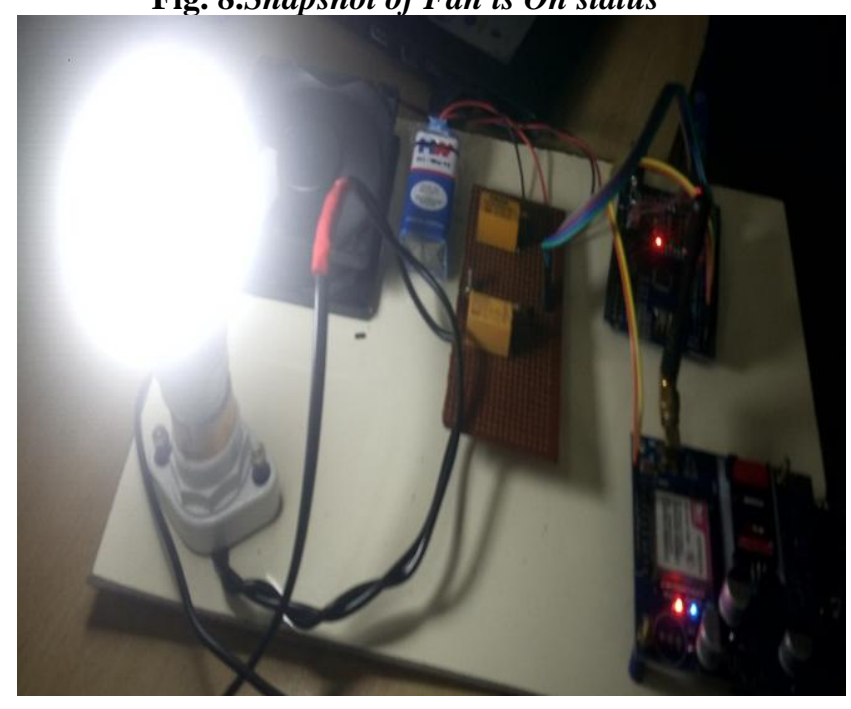

Fig. 9.Snapshot of Fan is On Status

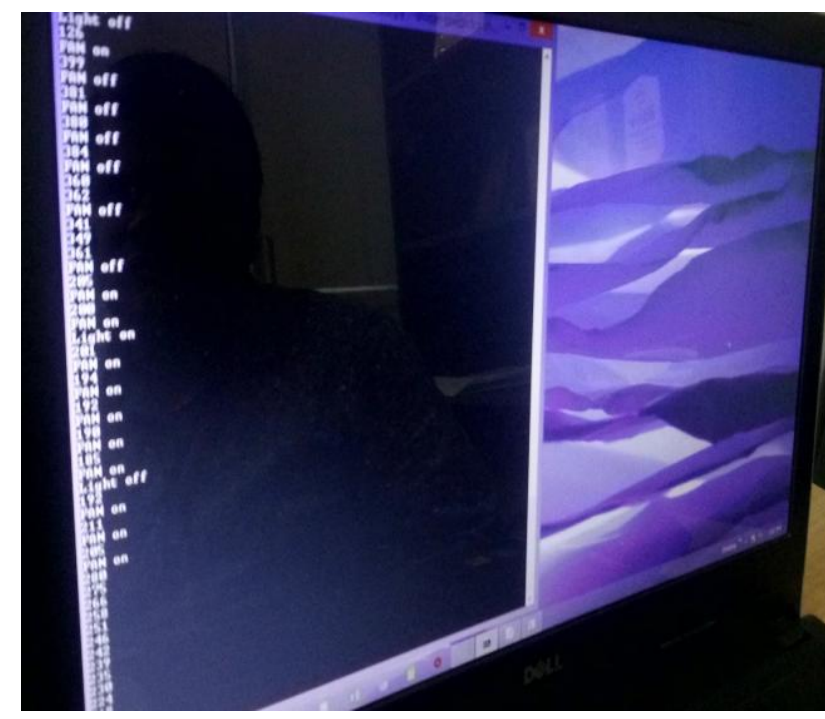

Fig. 10. Snapshot of Fan is On in Software

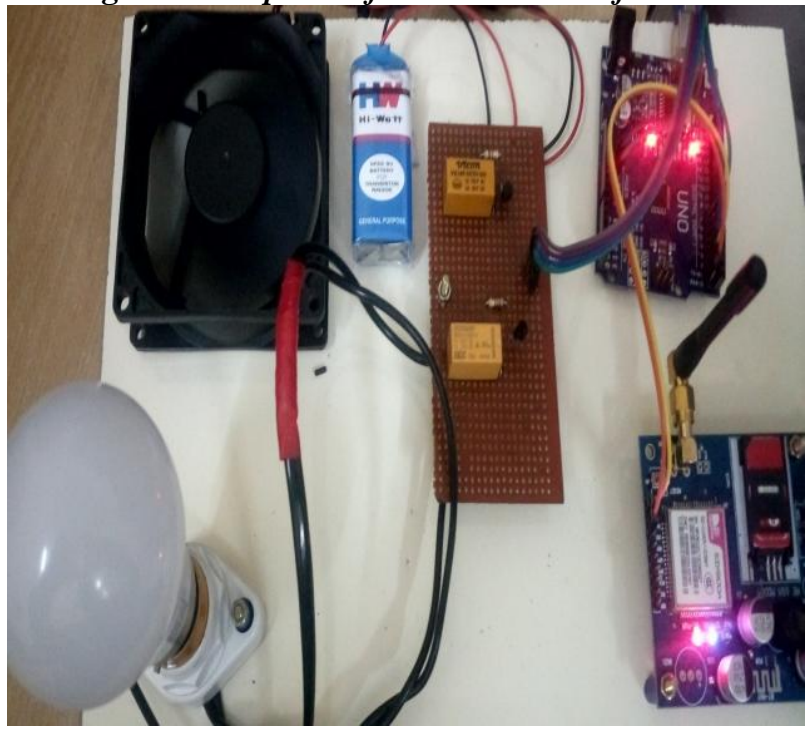

Fig. 11. Snapshot of Fan is On status in Prototype

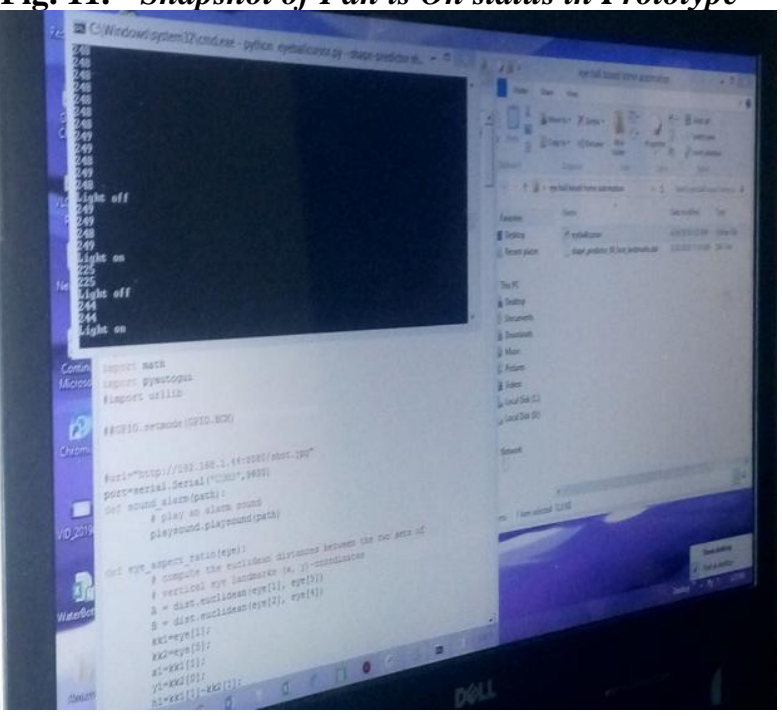

Fig. 12. Snapshot of Module

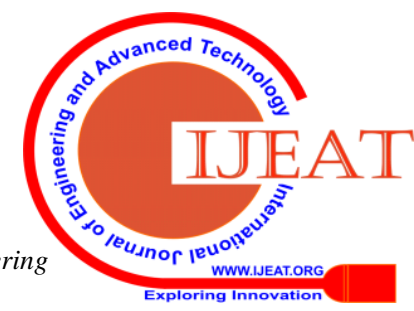




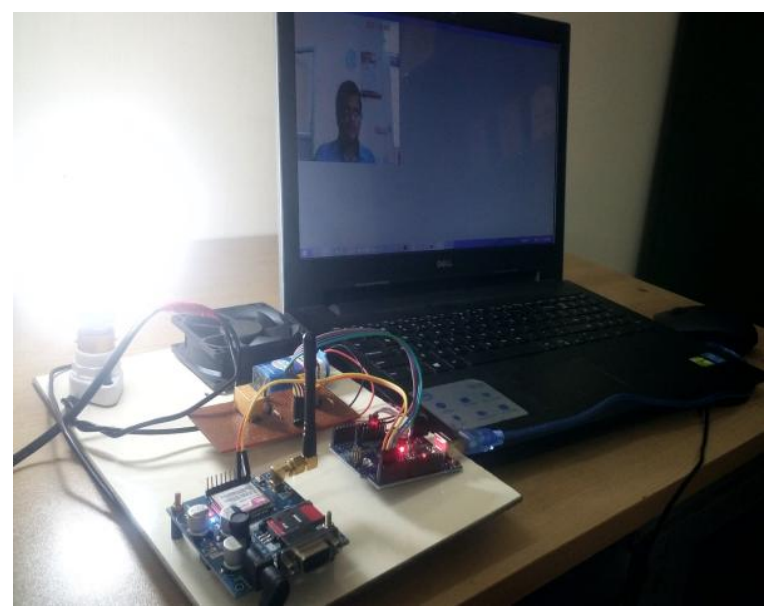

Fig. 13. Snapshot of Working status

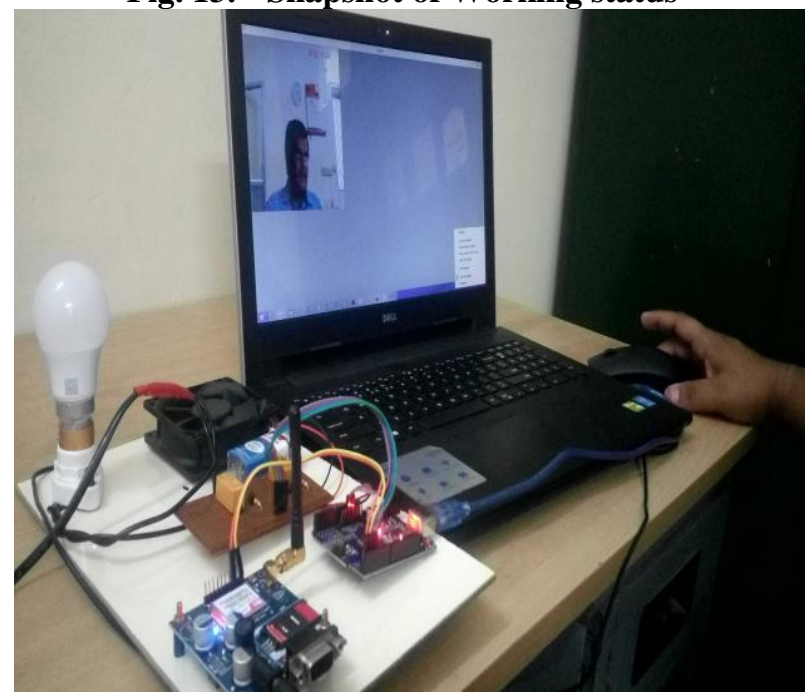

Fig. 14. Snapshot of Experimentation

\section{CONCLUSION}

In the demonstration of the prototype, the results provide by eye-tracking results in operation of the devices connected in Home, which helps the disabled persons a great extent.

\section{REFERENCES}

1. D. N. Perkins, C. Hancock, R. Hobbs, F. Martin and R. Simmons, "Conditions of learning in novice programmers", Journal of Education and Computing Research, Vol. 2, pp. 37-55, 1986.

2. S. $\mathrm{Xu}$ and $\mathrm{V}$. Rajlich, "Cognitive process during program debugging”, Proceedings of the $3^{\text {rd }}$ IEEE International Conference on Cognitive Informatics, Victoria,Canada,2004, pp.176-182.

3. P. Viola and M. Jones, "Rapid Object Detection using a Boosted Cascade of Simple Features", Proceedings of the 2001 IEEE Computer Society Conference on Computer Vision and Pattern Recognition, Kauai,HI,USA,2001,pp.I-I.

4. J. A. Villalobos and N. A. Calderón, "Developing programming skills by using interactive learning objects," in Proceedings of the 14th annual ACM SIGCSE conference on Innovation and Technology in Computer Science Education, 2009, pp. 151-155.

5. A.M.Malla, P.R.Davidson, P.J.Bones, R. Green and R.D.Jones, "Automated Video-base Measurement of Eye Closure for Detecting Behavioral Microsleep", 2010 Annual International Conference of the IEEE Engineering in Medicine and Biology, Buenos Aires, Argentina, 2010,pp.6741-6744.

6. S. Vitabile, A.D.Paola and F. Sorbello, "Bright Pupil Detection in an Embedded, Real-time Drowsiness Monitoring System", 2010 24th IEEE International Conference on Advanced Information Networking and Applications, Perth, 2010, pp.661-668.

7. E. Verdú et al., "A distributed system for learning programming on-line", Computers \& Education, Vol. 58, no. 1, pp. 1-10, 2012.
8. G. Boustany, A. El Deen Itani, R. Youssef, O. Chami and Z. O. Abu-Faraj, "Design and development of a rehabilitative eye-tracking based home automation system", 2016 3rd Middle East Conference on Biomedical Engineering (MECBME), Beirut, 2016, pp. 30-33.

9. A. Rajesh and M. Mantur, "Eyeball gesture controlled automatic wheelchair using deep learning", 2017 IEEE Region 10 Humanitarian Technology Conference (R10-HTC), Dhaka, 2017, pp. 387-391.

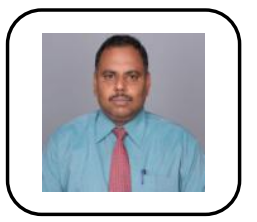

\section{AUTHORS PROFILE}

Dr.D.Vijendra Babu earned his Ph.D. from Jawaharlal Nehru Technological University, Hyderabad, M.Tech. from SASTRA Deemed to be University \& B.E. from University of Madras. He is currently designated as Vice Principal \& Professor. He has 2 Decades of Experience in the field of Education, Research \& Administration at various levels. He has served as HoD for 13 Years \& delivered numerous Invited Lectures in the area of 5G Communication, Artificial Intelligence, Robotics \& Image/Video Processing at various Institutions. He has chaired several Sessions on International/National Conferences. He has published $80+$ papers in International Journals/Conferences. He is a recipient of Best Paper Award in IEEE International Conference \& Active ISF Award. He is Secretary of IEEE Robotics \& Automation Society. He is Senior Member of IEEE, Fellow of IETE, Life member in ISTE, BES (I), ACEEE \& IACSIT.

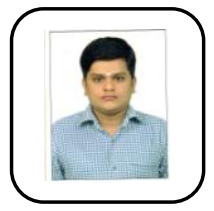

S.K.Sivasubramanian completed his B.E. degree from Vinayaka Mission's Research Foundation, Deemed University and pursuing his M.E.(Embedded Systems technology) in VMRF,DU. 